\title{
Comparison of orotracheal versus nasotracheal fibreoptic intubation in simulated cervical spine patients, under conscious sedation
}

\author{
Tarang Jain ${ }^{1, *}$, Lalit Gupta ${ }^{2}$, Manoj Bhardwaj ${ }^{3}$ \\ ${ }^{1,2}$ Assistant Professor, ${ }^{3}$ Professor, Dept. of Anaesthesia, ${ }^{1}$ ESI-PGIMSR, Basaidarapur, New Delhi, ${ }^{2,3}$ Maulana Azad Medical \\ College, Delhi, India
}

*Corresponding Author: Tarang Jain

Email: dr.tarang@yahoo.co.in

Received: $19^{\text {th }}$ July, 2018

Accepted: $27^{\text {th }}$ July, 2018

\begin{abstract}
Introduction and Aims: Airway management in a patient with cervical spine injury is considered a challenge. Minimizing neck movement and maintaining head in neutral position is essential to prevent secondary neurological injury. Flexible fibreoptic intubation causes minimal cervical spine movement. In this study, we evaluated and compared orotracheal and nasotracheal flexible fibreoptic intubation in a patient with simulated cervical spine injury (using a cervical collar), under conscious sedation.

Materials and Methods: Sixty patients were randomly allocated into oral and nasal groups. After premedication and preperation with Xylometazoline nasal drops and lignocaine nebulization, bolus fentanyl and propofol infusion was started to achieve concious sedation. Flexible fibreoptic intubation was performed orally or nasally, after placement of a cervical collar. Operator ease and hemodynamics were monitered.

Result: In the oral group, $86.7 \%$ and in the nasal group, 93.3\% first attempts were successful. The ease of fibreoptic intubation was graded to be excellent in a significantly greater number of patients in the nasal group as compared to the oral group. Hemodynamic variability though present was not clinically relevent, this might have been secondary to use of adequate sedation. Conclusion: The ease of fibreoptic intubation in simulated cervical spine injury, under conscious sedation was found to be significantly better in the nasotracheal group. Hemodynamic stability was demonstrated in both the groups in our study.
\end{abstract}

Keywords: Cervical spine, Simulated cervical spine, Fibreoptic intubation, Oral fibreoptic intubation, Nasal fibreoptic intubation, Conscious sedation.

\section{Introduction}

Cervical spine injured patients present an airway management challenge, as any movement of the cervical spine exacerbates the injury. ${ }^{1}$ Presence of cervical collar prevents neck movement but can cause reduction in mouth opening, this makes laryngoscopy difficult and impairs visualization of the glottic opening. ${ }^{2,3}$ Fibreoptic intubation is an established method of securing airway in patients having cervical spine injury. Rosenblatt et $\mathrm{al}^{4}$ and Lord et $\mathrm{al}^{5}$ have advocated use of bronchoscope for intubation in cervical spine injury patients. Flexible fibreoptic intubation causes minimal cervical spine movement, and is the gold standard for intubation in suspected cervical spine injury. ${ }^{6,7}$

Fibreoptic intubation has been carried out successfully in patients with cervical spine injury via both the oral and nasal route, but literature lacks comparison among these two methods. In this study, we evaluated and compared orotracheal and nasotracheal flexible fibreoptic intubation in a patient with simulated cervical spine injury (using a cervical collar), under conscious sedation.

This study was conducted in the Department of Anesthesiology and Intensive Care, MAMC and LNH after approval from Ethical committee and institutional review board clearance. The study was conducted on 60 patients ASA 1-2, aged 20-50 years admitted in Lok Nayak Hospital, New Delhi undergoing elective surgery, other than neck surgery, requiring endotracheal intubation after obtaining consent. Randomization done using a computer generated random number table. Patients having difficult airway, hypertension or use of drugs modifying blood pressure, Respiratory/Cardiac/Esophageal disease, and difficult nasal route/any contraindication to nasal intubation and having increased risk of gastric aspiration were excluded from the study.

\section{Materials and Methods}

All the patients were premedicated with $0.25 \mathrm{mg}$ Alprazolam night before and 2 hours prior to start of the surgery. Topical anaesthesia of the airway was achieved by nebulization with $5 \mathrm{ml}$ of $4 \%$ Lignocaine. Xylometazoline nasal drops were put twice at an interval of 15 minutes in all patients to achieve vasoconstriction. All patients received glycopyrrolate $(0.2 \mathrm{mg}$ intramuscular) thirty minutes before shifting to operation theatre. Five minutes after giving midazolam $(0.03 \mathrm{mg} / \mathrm{kg})$ and fentanyl $(1.5 \mu \mathrm{g} / \mathrm{kg})$ intravenously, Propofol $0.5 \mathrm{mg} / \mathrm{kg}$ was given followed by an infusion of $50 \mu \mathrm{g} / \mathrm{kg} / \mathrm{min}$ to achieve conscious sedation. Oxygen was given at $41 / \mathrm{min}$ via nasal canula and continued during the fibreoptic intubation using the working channel of the fibrescope. The semirigid collar used to simulate cervical spine injury was inserted after giving sedation.

Fiberscope loaded with predetermined sized ( 6.5 for females, 7.5 for males) endotracheal tube was introduced 
through oral or nasal rout and on visualization of the glottic opening; vocal cords were sprayed with $2 \mathrm{ml}$ of $2 \%$ lignocaine through the working channel of the fiberscope. This process was repeated after the fiberscope had crossed the vocal cords. When the carina was visible an endotracheal tube of size 7.5 in males and size 6.5 in females was guided into place (3-4 $\mathrm{cm}$ above the carina) and then Bains circuit was connected and intubation was confirmed by appearance of $\mathrm{Et} \mathrm{CO}_{2}$ graph. General anaesthesia was then provided by giving propofol $(0.5 \mathrm{mg} / \mathrm{kg})$, vecuronium $0.1 \mathrm{mg} /$ and isoflourane at $0.8 \%$ through Bains circuit.

Sedation score of the patients and vitals (NIBP, PR, and $\mathrm{SpO} 2$ ) were monitored before starting fibrescopy. Patient's consciousness was assessed and propofol infusion was adjusted to attain Ramsay Sedation score 3.During fibrescopy and intubation, maneuvers to clear airway like chin lift, jaw thrust and $180^{\circ}$ rotation of endotracheal tube over fiberscope were performed, when required. A total of three attempts were made. Inability to intubate despite applying airway clearing maneuvers (chin lift and jaw thrust) and of $180^{\circ}$ rotation of endotracheal tube over fiberscope was considered as a failure of securing airway, following which the cervical collar was removed the patient paralyzed and intubated using direct laryngoscopy.

The operator performing the procedure graded the ease of handling at previously determined points, which included insertion of fibroscope, visualization of glottic opening, sliding of endotracheal tube and overall ease of handling, as difficult, easy and excellent.

The patients were asssesed for sore throat, 2 hours and 24 hours after completion of the surgery.

Data was statistically analyzed as Mean \pm SD with 95\% confidence interval. Comparision of two Means for continuous variables such as heart rate, blood pressure, and mean arterial blood pressure was performed using the Student $-t$ test and non-parametric variables using
Mann-Whitney test. For categorical variables Chisquare/Fischer exact test was used. Intragroup comparison at two points in time was done using Paired t-test and for non-parametric variables using Wilcoaxon signed rank test. A p value of $<0.05$ was considered statistically significant.

\section{Observation}

Sixty patients were included in this study. Demographic characteristics including age, height, weight, body mass index, gender, and criteria of airway assessment were found comparable and statistically insignificant $(p>0.05)$

A total of three attempts were allowed in the study. In the oral group, $86.7 \%$ (26/30) intubations were successful in the first attempt and 6.7\% (2/30) in the second attempt. Two patients $(6.7 \%)$ could not be intubated in the third attempt also. In the nasal group, $93.3 \%(28 / 30)$ were successful in the first attempt and $3.3 \%(1 / 30)$ in the second attempt. The third attempt was unsuccessful in one patient in the nasal group. In all three patients, a failure to intubate was because of inability to slide the tube over the fibrescope beyond a certain point, $16 \mathrm{~cm}$ in the oral and $20 \mathrm{~cm}$ in the nasal (Table 1). More airway clearing maneuvers were required in the oral group for visualization of the epiglottis $(50 \%)$ as compared to the nasal group (33.33\%), the difference was not statistically different( $p$ value $>$ nasal group).The mean insertion time was more in the nasal group (2.8 min) compared to the oral group (2.7 min), though the difference was not statistically significant.

The ease of fibreoptic intubation was graded to be excellent in a significantly greater number of patients in the nasal group as compared to the oral group with regards to the visualization of the epiglottis $(100 \%$ vs $73.3 \%$ ) and advancement of fibrescope into the glottic opening $(96.7 \%$ versus $70 \%: \mathrm{p}<0.05)$.

Table 1: Results of oral/nasal fibreoptic intubation

\begin{tabular}{|c|c|c|}
\hline Parameters & Oral Group & Nasal Group \\
\hline Successful Fibreoptic Intubation & $28 / 30$ & $29 / 30$ \\
\hline First Attempt & $26 / 30$ & $28 / 30$ \\
\hline Second Attempt & $2 / 30$ & $1 / 30$ \\
\hline Mean intubation Time & $162.68 \mathrm{sec}(86-295)$ & $169.9 \mathrm{sec}(90-230)$ \\
\hline Reason of failure of intubation: (n) & $\begin{array}{l}\text { 1. Inability to advance ETT at level of } \\
\text { pyriform fossae (2) } \\
\text { 2. Obstruction to passage of ETT beyond } \\
\text { tip of fiberscope (2) } \\
\text { 3. Inability to advance the ETT beyond } \\
\text { the pyriform fossae(2) }\end{array}$ & $\begin{array}{l}\text { 1. Inability to advance ETT due to } \\
\text { obstruction in nasal cavity(1) } \\
\text { 2. Patient movement leading to esophageal } \\
\text { intubation(1) } \\
\text { 3. Inability to advance ETT due to } \\
\text { obstruction at level of pyriform fossae(1) }\end{array}$ \\
\hline Airway clearing maneuvers & $15 / 30$ & $10 / 30$ \\
\hline Chin Lift & $11 / 15$ & $10 / 10$ \\
\hline Jaw Thrust & $4 / 15$ & Nil \\
\hline $\begin{array}{l}\text { Propofol Increment dose(mg) Mean } \\
\pm \text { SD }\end{array}$ & $42.0(29.2)$ & $36.3(15.6)$ \\
\hline Incidence of limb movement & $11 / 30$ & $9 / 30$ \\
\hline Incidence of cough & $7 / 30$ & $4 / 30$ \\
\hline Desaturation & $15 / 30$ & $13 / 30$ \\
\hline Sore throat & $13 / 30$ & $9 / 30$ \\
\hline
\end{tabular}


All the patients in both groups remained hemodyanamically stable throughout the procedure. On comparision, after intubation the pulse rate, SBP, DBP,MAP were lower in the oral group and the difference was found to be statistically significant, $\mathrm{p}$ value of $<0.05$ (Graph 1,2,3).

Graph 1: Comparison of pulse rate

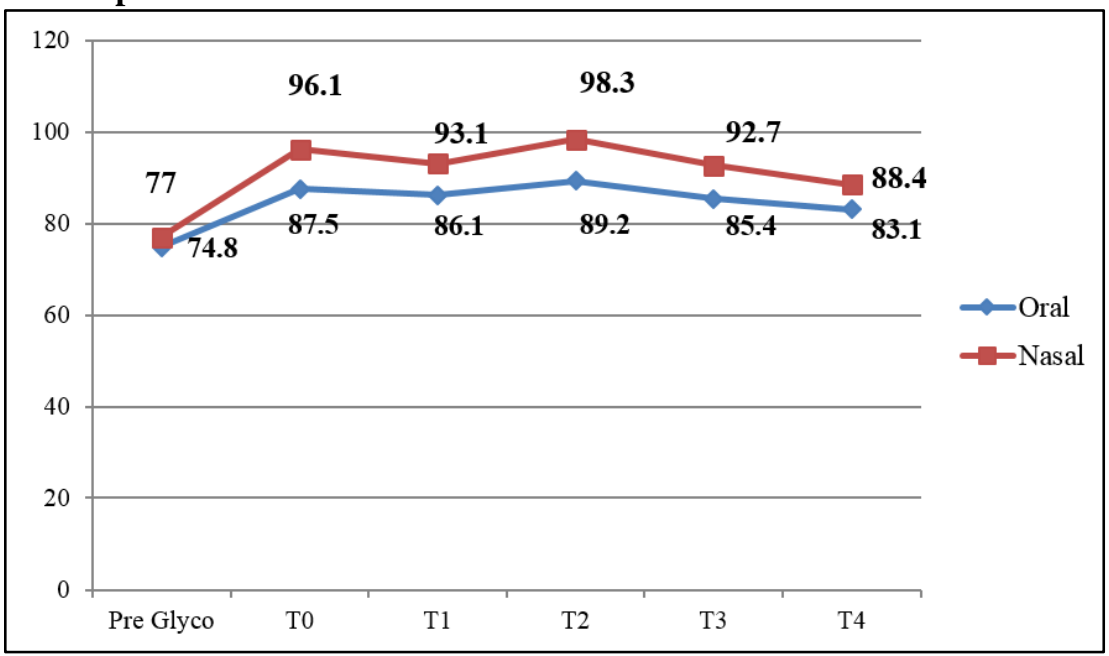

(Significant post intubation (T2) variation seen p: 0.031)

Graph 2: Comparison of systolic blood pressure

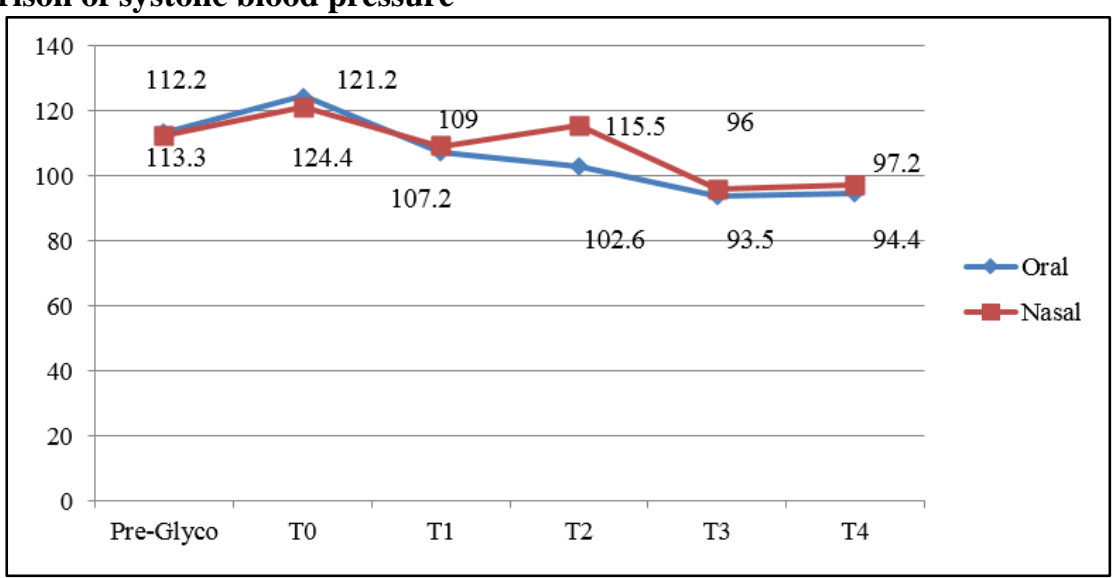

(Significant post intubation (T2) variation seen p: 0.001)

\section{Graph 3: Comparison of diastolic blood pressure}

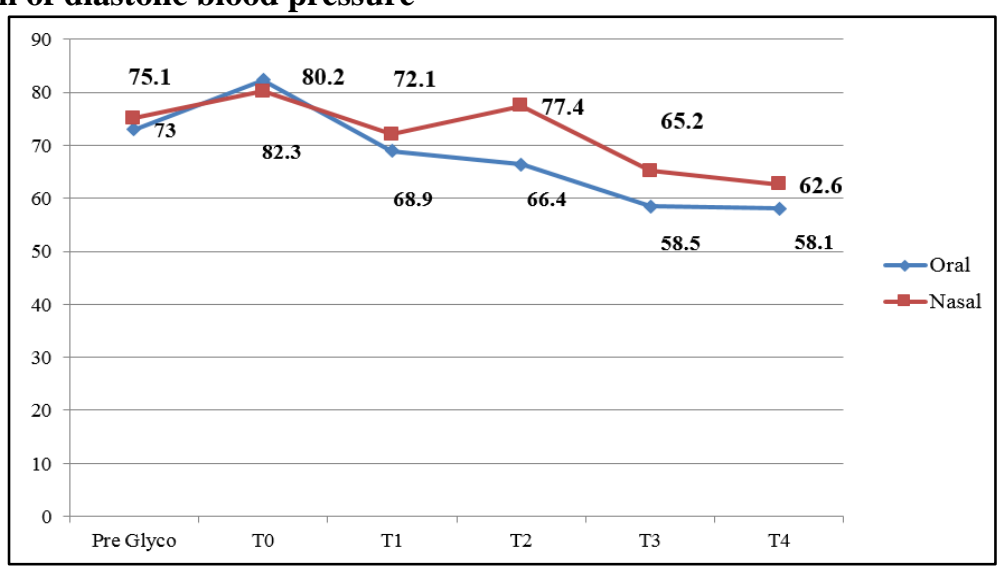




\section{Graph 4: Comparison of mean blood pressure}

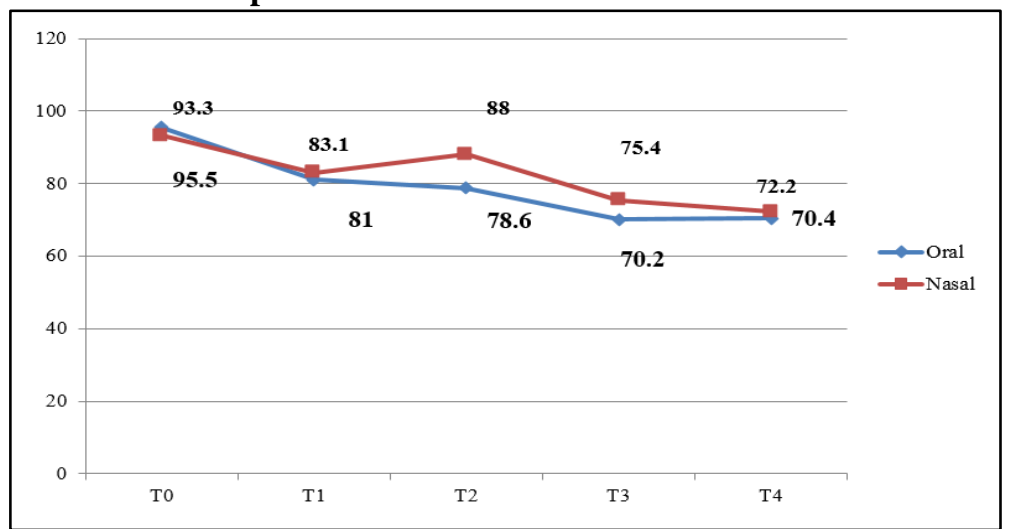

(Significant post intubation (T2) variation seen p: 0.005

\section{Discussion}

Use of the fibreoptic bronchoscope to facilitate tracheal intubation in cervical spine-injured patients has been advocated by neuroanesthesia experts' nationwide ${ }^{8}$ with stabilization of the cervical spine. The patient's protective reflexes are largely left intact and a neurologic assessment can be made after intubation to ensure that there has been no change in the patient's status. ${ }^{1}$ Use of sedation has resulted in better patient cooperation and comfort. These considerations support the use of the tracheal intubation facilitated by a fibreoptic bronchoscope in the management of the airway of cervical spine injury patients. Both orotracheal and nasotracheal routes can be used for fibreoptic intubation. However, there is no clinical outcome data suggesting better ease and safety comparing the two routes in cervical spine injury. This prospective randomized controlled study was conducted to compare the ease, safety and hemodynamic changes between orotracheal and nasotracheal fibreoptic intubation, in simulated cervical spine injury, under conscious sedation, under comparable doses of midazolam, fentanyl and propofol

The two groups were demographically comparable with respect to the sex, weight, height and body mass index distribution, ASA Grading and MMPC. Success rate of intubation was $93.3 \%(\mathrm{n}=30)$ in Oral Group (O) and $96.7 \%(\mathrm{n}=30)$ in Nasal Group (N). The first attempt success rate was $86.7 \%$ in the oral group and $93.3 \%$ in the nasal group. Two cases in the oral group and one case in the nasal group were successful in the second attempt in the oral group, fibreoptic intubation was achieved without any maneuver in $50 \%$ patients in the oral group and $66.7 \%$ patients in the nasal group. Chin lift was the most commonly used maneuver used in $36.6 \%$ of the cases in the oral group and $33.3 \%$ cases in the nasal group. Jaw thrust was used in $13.3 \%$ patients in the oral group and was not required in any patient in the nasal group.

In a similar study Sharma et $\mathrm{al}^{9}$ had a success rate of $60 \%$ in the first attempt, which increased to $100 \%$ after removal of endotracheal tube by $5 \mathrm{~cm}$ and railroading after $90^{\circ}$ rotation. This high rate of unsuccessful intubation in the first attempt in the study by Sharma et al could be due to a larger size of tube used - size 7 in female and 8 in male patients. In our study, relatively small size of endotracheal tube and opening of the airway by the chin lift maneuver might have led to better success rate in the first attempt.

The success rate of nasotracheal fibreoptic intubation in our study was similar to the study by Fuchs et $\mathrm{al}^{10}$ with a success rate of $96.3 \%$ in 327 neurosurgical patients who underwent intubation under general anesthesia. Their failure rate of $3.6 \%$ was due to nasal anatomic abnormalities preventing trans-nasal insertion of endotracheal tube. In their study they have not mentioned if any maneuver to facilitate intubation was attempted. Woodall et $\mathrm{al}^{11}$ had a failure rate of $10 \%$ of patients, with awake fibreoptic nasal intubation. They attributed the failure to intubate due to anatomic reasons in 10 patients and inadequate anesthesia in 8 patients. In our study, patients were optimally sedated and topicalized which might have led to better success rate.

The mean insertion time in our study was $162.68 \mathrm{sec}$ in the oral group and $169.97 \mathrm{sec}$ in the nasal group the insertion time reported by Sharma et $\mathrm{al}^{9}$ in their study was $11 \mathrm{sec}$ for orotracheal fibreoptic intubation. This was significantly less as compared to our study due to different start and end times. They defined the insertion time as the time from starting advancement of the tracheal tube to withdrawal of the fibrescope. This was different from our study where we considered the time from entry of scope into oral cavity to confirmation of endotracheal tube placement.

The insertion time reported by Fuchs et $\mathrm{al}^{10}$ for nasotracheal fibreoptic intubation was $7.3 \mathrm{~min}$, with a range of 2-50 min. Their insertion time started from application of cocaine to the nasal mucosa and ended at positioning of the endotracheal tube. This may have been responsible for the longer time taken in their study. This differed from our study; our insertion time was from insertion of fibrescope into the nasopharynx to confirmation of endotracheal tube placement.

In the nasal group, handling of the fibrescope was significantly better than the oral group during visualization of epiglottis and advancement of 
fibrescope into the glottic opening. The ease of insertion of the fibrescope through the oro/nasopharnyx and ease of intubation, sliding of endotracheal tube was found to be similar in both the groups. On overall grading and scoring there was statistically better ease of intubation seen in the nasal group as compared to the oral group.

There is a lack of evidence in literature regarding subjective assessment of fibreoptic intubation. Though Asai and Shingu ${ }^{12}$ in their review article have mentioned a variability of $0-90 \%$ in the incidence of difficulty in sliding the endotracheal tube in fibreoptic orotracheal intubation. The studies of Asai and Marsh et al reported an incidence of $83 \%$ and $90 \%$ difficulty in sliding the tube in their studies respectively. They reported an incidence of $10-90 \%$ difficulty in sliding the endotracheal tube in nasotracheal fibreoptic intubation. The studies of Jones and Barker reported an incidence rate of $73 \%$ and $50 \%$ in their studies respectively. In these studies, the assessment criteria were not defined clearly. Further, the assessment was graded only with regards to sliding of tube and not the ease of insertion, handling of the fibrescope and visualization of glottic opening considered in our study.

The saturation was $>95 \%$ in all patients, providing oxygen at $4 \mathrm{~L} / \mathrm{min}$ via nasal cannula, prior to fibroscopy. Desaturation $\left(\mathrm{SpO}_{2}<90 \%\right)$ occurred in two cases in the oral group while sliding the endotracheal tube over the fibrescope, after giving an incremental dose $(10 \mathrm{mg})$ of propofol on patient movement. The first attempt was abandoned as the patients went into apnea. Propofol infusion was stopped and 100\% oxygen given in both cases. The second attempt in both the cases was successful, without any episode of desaturation. Woodall et $\mathrm{al}^{11}$ in their study provided supplemental oxygen via nasal cannula in all patients during awake fibreoptic intubation. They reported three cases of hypoxia occurred, these incidences of hypoxia occurred despite lack of sedation. Fuchs et $\mathrm{al}^{10}$ in a similar study reported a saturation of less than $90 \%$ in $11.6 \%$ of cases, with saturation being less than $80 \%$ in 4 patients. They attributed this to over sedation or inadequate local anesthesia and bronchospasm. They have not mentioned whether oxygen was provided to the patients in their study.

The sedation scores of the patient were assessed as per the Ramsay Sedation Score at different steps during fibreoptic intubation, they stayed at 3 or 4 for the duration of the procedure. Spontaneous respiration was present in the patients at all points of time.

Laryngospasm occurred in two patients in the oral group and one patient in the nasal group. It occurred on spraying lignocaine through the working channel of the scope and resolved on it's own after 30 seconds. This could have been due to local anesthetic action of lignocaine which resolved the spasm.

Cough was present in 7 (23.33\%) patients in the oral group and $4(13.33 \%)$ patients in the nasal group. In our study, propofol was given to suppress further coughing in these patients. This was similar to that reported by Sharma et al. ${ }^{9}$ They reported an incidence rate of cough as occurring in $25.71 \%$ of patients their study. Coughing leading to head and neck movement, is deleterious in cervical spine injury patients. Our study may be lacking in adequacy of topicalization of the airway. This might have led to airway stimulation and coughing.

Bleeding was present in $6.6 \%$ of patients in the oral group and $13.3 \%$ of patients in the nasal group (It was noticed to be minor in all the patients and did not interfere with the fibreoptic attempt. Woodall et $\mathrm{al}^{11}$ and Fuchs et al, ${ }^{10}$ reported an incidence of $10 \%$ and $8.8 \%$ incidence of minor bleeding.

Thirteen patients (44.8\%) in the oral group and nine patients $(30 \%)$ in the nasal group complained of sore throat after 2 hours. The sore throat resolved in 36 hours, without any intervention. Fuchs et $\mathrm{al}^{10}$ found the incidence rate of sore throat as $6 \%$ in their study. This is considerably higher than our study; however the time period for the observation has not been mentioned in their study. Woodall et $\mathrm{al}^{11}$ found the incidence rate of sore throat to be $35 \%$ in their study. This could have been due to the multiple attempts of fibreoptic intubation in their study.

The change in pulse rate and systolic and diastolic blood pressure in the oral group remained insignificant when compared at different time intervals but in the nasal group on comparison at different time intervals, increase was significant after intubation (T2) when compared to the post sedation value (T1). When the two groups were compared, the rise in was more in the nasal group as compared to the oral group after intubation (T3). This difference between the two groups was statistically significant. This could be due to increased airway stimulation, as the fibrescope and endotracheal tube had to traverse a longer route via the nasal cavity. This change was however not clinically important. The hemodynamic stability demonstrated in both the groups in our study, could have been due to optimum topicalization and adequate sedation, which blunted the response caused by airway stimulation.

Xue et $\mathrm{a}^{13}$ in their study showed that both fibreoptic orotracheal and nasotracheal intubation cause significant increases in pulse rate and blood pressure. In both the oral and nasal routes in their study, there was a significant rise in systolic and diastolic as well as mean arterial pressure and pulse rate as compared to the post induction values. This rise was more in the nasal group as compared to the oral group though this was not significant. The blood pressure returned to the post induction values in both groups within 3 minutes though pulse rate in the oral group settled comparatively later than the nasal group. They have postulated that this difference in the post intubation response between oral and nasal routes is due to greater stimulation of airway structures in the nasal group. This could be due to insertion of fibreoptic scope and endotracheal tube through the nasal cavity leading to greater circulatory 
response. In a similar study Woodall et $\mathrm{al}^{11}$ on awake nasotracheal fibreoptic intubation, found that the increase in systolic blood pressure per subject ranged from $0-63 \mathrm{~mm} \mathrm{Hg}(0-53 \%)$, while the increase in heart rate ranged from $0-59$ beats per minute. They concluded that hemodynamic stability had been lost as a consequence of avoiding sedation. In our study, adequate sedation may have been responsible for the hemodynamic stability seen. Williams et $\mathrm{al}^{14}$ in their study demonstrated an average increase in mean arterial pressure of $16.2 \%$ with a range of $1-33.3 \%$. The heart rate values in their study were more variable, with an average increase of $30.2 \%$ and a range of $0-158.3 \%$. This variability could have been due to avoidance of sedation in their study.

\section{Conclusions}

The ease of fibreoptic intubation in simulated cervical spine injury, under conscious sedation was found to be significantly better in the nasotracheal group. Hemodynamic stability was demonstrated in both the groups in our study.

\section{Conflicts of Interest: None.}

\section{References}

1. Crosby ET. Airway management in adults after cervical spine trauma. Anesthesiol. 2006;104(6):1293-318.

2. Graham JJ. Complications of cervical spine surgery-A five-year report on a survey of the membership of the Cervical Spine Research Society by the Morbidity and Mortality Committee. Spine. 1989;14:1046-1050.

3. Sahin A, Salman MA, Erden A, Aypar U. Upper cervical vertebrae movement during intubating laryngeal mask, fibreoptic and direct laryngoscopy: a video-flouroscopic study. Eur J Anaesthesiol. 2004;21:819-823.

4. Rosenblatt WH, Wagner PJ, Ovassapian A, Zain ZN. Practice patterns in managing the difficult airway by anesthesiologists in the United States. Anesth Analg. 1998;87:153-157.

5. Lord SA, Boswell WC, Williams JS, Odon JW, Boyd CR. Airway control in trauma patients with cervical spine fractures. Prehosp Disas Med. 1994;9:44-49.
6. Wong DM, Prabhu A, Chakraborty S, Tan G, Massicotte EM, Cooper R. Cervical spine motion during flexible bronchoscopy compared with the Lo-Pro Glidescope. $\mathrm{Br}$ J Anaesth. 2009;102(3):424-430.

7. Byhahn C, Nemetz S, Brietkreutz R, Zwissler B, Kaufmann M, Meininger D. Tracheal intubation using the Bonfils intubation fibrescope or direct laryngoscopy for patients with a simulated difficult airway. Can J Anesth. 2008;55(4):232-237.

8. Koerner IP, Brambrink AM. Fiberoptic techniques. Best Pract Res Clin Anaesthesiol. 2005;19(4):611-621.

9. Sharma D, Bithal PK, Rath GP, Pandia MP. Effect of orientation of a standard polyvinyl chloride tracheal tube on success rates during awake flexible fibreoptic intubation. Anaesthesia. 2006;61(9):845-848.

10. Fuchs G, Schwarz G, Baumgartner A, Kaltenböck F, Voit-Augustin H, Planinz W. Fiberoptic intubation in 327 neurosurgical patients with lesions of the cervical spine. $J$ Neurosurg Anesthesiol. 1999;11(1):11-16.

11. Woodall NM, Harwood RJ, Barker GL. Complications of awake fibreoptic intubation without sedation in 200 healthy anaesthetists attending a training course. $\mathrm{Br} \mathrm{J}$ Anaesth. 2008;100(6):850-855.

12. Asai T, Shingu K. Difficulty in advancing a tracheal tube over a fibreoptic bronchoscope: incidence, causes and solutions. Br J Anaesth. 2004;92(6):870-881.

13. Woodall NM, Harwood RJ, Barker GL. Complications of awake fibreoptic intubation without sedation in 200 healthy anaesthetists attending a training course. $\mathrm{Br} \mathrm{J}$ Anaesth. 2008;100(6):850-855.

14. Williams KA, Barker GL, Harwood RJ, Woodall NM. Combined nebulization and spray-as-you-go topical local anaesthesia of the airway. Br J Anaesth. 2005;95(4):549553.

How to cite this article: Jain T, Gupta L, Bhardwaj M. Comparison of orotracheal versus nasotracheal fibreoptic intubation in simulated cervical spine patients, under conscious sedation. Indian J Clin Anaesth. 2018;5(4):603608. 